\title{
Leeds Meeting of the Institution of Gas Engineers.
} THE Institution of Gas Engineers met in Leeds for presidency of Mr. C. S. Shapley, manager of the Leeds Gas Department. Several of the papers dealt with questions of actuality in the world of carbonisation.

Mr. E. G. Stewart examined the "Functions of Coke Ovens " in a paper of great interest in view of the recent issue of the report of the Area Gas Supply Committee. His analysis revealed that only about four British gas undertakings are large enough to consider the installation of such plant, although a group of smaller undertakings might do so. The coke ovens should rationally be attached to iron and steel works, which need the gas as fuel. If that were generally the case, there would be no coke oven gas to spare. As gas-making plant, the coke oven is not superior to the modern vertical retort, which is more flexible. The development of coking plants increases the pressure on the coke market, which will be intensified if the gas works purchase spare gas. This points to the need for an understanding between the two industries for the marketing of both main and by-products.

The need for greater freedom in constructing the tariffs for the sale of gas was emphasised so that differential prices might be charged according to the incidence of the load. Indeed, the freedom to rationalise the charging for gas was advanced on all sides as an essential preliminary to rationalising the supply of industrial gaseous fuel.

Dr. E. W. Smith summarised the experience gained in the process of dehydrating coal gas before distribution. This is a notable innovation introduced into practice by a British firm in 1925. By washing the gas with a strong solution of calcium chloride (glycerine has also been proposed) about two-thirds of the water normally present in coal gas is removed. The principal advantage is that the dew point of the gas is so far reduced that liquid water is never deposited in the mains and consequently corrosion of mains and meter, etc., is almost entirely prevented. Stoppages due to water and ice are avoided in winter, and many other advantages accrue, so that plants for the purpose are being erected with great rapidity and the practice is being adopted in foreign works.

Mr. F. Prentice deseribed three vears' experience with a waterless gasholder, of which a few already exist in Great Britain. The first was erected about fifteen years ago in Germany, where these holders are now numerous--indeed they are probably the most characteristic feature of the landscape in the Ruhr valley. The normal gasholder consists of a bell floating in water, but these consist essentially of a vertical cylinder closed by a piston, which rises and falls as the volume of gas in the holder changes. The piston is made gas-tight either by a tar seal or a grease joint at its periphery where sliding contact is made with the walls. Hailed at first as a piece of crazy engineering foredoomed to failure, a few years have falsified practically all of the prophecies, and many more will be seen in the future. The Ipswich holder, which is
$202 \mathrm{ft}$. high, is only a small one and the large examples are undoubtedly wonderful engineering constructions.

A paper by Mr. C. F. Broadhead of Melbourne dealt with the production of a new road binder-bitural. The paper has a bearing on the problem of current importance to all carbonising industries. There is an over-production of tar, with consequent difficulty in marketing in the face of mineral road-making materials-bitumen and oil pitch. It is said that the tar from modern vertical retorts is not so good a roadmaking material as the old tar. Mr. Broadhead attributes this to the large proportion of unsaturated hydrocarbons in vertical retort tar, and proposes to polymerise these by air oxidation in the presence of an accelerator which induces condensation of the unsaturated hydrocarbons with phenols to form larger molecular aggregations. The tar is substantially altered in chemical character, and is said to have given satisfactory results in Australia as a roadmaking material.

The paper by Messrs. W. H. Hoffert and G. Claxton on benzole recovery in gasworks practice discussed the important question as to whether it is worth while to remove benzole from town's gas for use as motor spirit. It has generally been assumed that it was not, and relatively little is so obtained. The view is being challenged as the result of faulty costing, and the gas works will probably become much more prominent in this direction. The refining of benzole involves a loss of good fuel which has long been recognised as a challenge to the inventive. The authors rletailerl their method of adding to the crude spirit suitable anti-oxidant inhibitors to prevent the formation of objectionable gums which result from the polymerisation of unsaturated hydrocarbons-essentially an oxidation process. This is an interesting piece of chemistry which promises to be of great practical importance to the motor spirit industry.

Dr. Margaret Fishenden's paper was a collation of methods for handling heat transmission calculations. In particular she gave the results of the application of the principle of similarity to correlate the results of measurements of convection, showing that the ob. servations of different workers could be closely haymonised in this way.

Prof. J. W. Cobb gave an account of the relations between the Institution of Gas Engineers and the University of Leeds extending back to 1906. The Institution lent encouragement to the establishment of a Fuel Department at the outset, and in 1910 endowed the chair in memory of the late Sir George Livesey. Since that time there has been close cooperation in the prosecution of investigations bearing on the problems of the industry. This is one of the earliest examples of co-operative industrial research in Great Britain, and the paper collated a large range of subjects which have been covered since that time. On the teaching side, it was stated that for years the demand for suitable graduates has been in excess of the men coming forward.
H. J. H.

\section{Visitation of the Royal Observatory, Greenwich.}

THE annual visitation of the Observatory took place on June 7. The Astronomer-Royal presented his report, which deals with the work of the Observatory during the year ended on May 10. The usual fundamental meridian work was carried on with the transit circle, the sun having been observed on 150 days, and the moon on 104 days. The excess of the moon's longitude over its tabular value was $5 \cdot 2^{\prime \prime}$; the excess has been diminishing since 1924 by nearly $\frac{1}{2}$ " per annum; the corresponding excess for the sun, which was $1 \cdot 7^{\prime \prime}$ in 1926 , has now fallen to $1 \cdot 6^{\prime \prime}$. The observation of stars in the zone $32^{\circ}$ to $64^{\circ}$ of declination will be completed this year. The next star catalogue will cover the zones $0^{\circ}$ to $24^{\circ}$, and $64^{\circ}$ to $90^{\circ}$; 
it is not now considered necessary to observe many stars fainter than magnitude 8 on the meridian; the positions of fainter stars are obtainable by photography with lenses of wide angle.

Observations with the Cookson floating zenith telescope now cover a period of nineteen years, which is the period of the great lunar nutation term. Dr. J. Jackson is discussing the observations, to deduce a new value for the coefficient of this term; it appears that the adopted value $9 \cdot 210^{\prime \prime}$ will not be altered by more than 0.002 ". The Gerrish drive, installed last year on the 28 -inch equatorial, has worked very well. 300 binaries were observed during the year, of which 56 were separated by less than $\frac{1}{2}$.

The determination of stellar parallaxes by photography with the Thompson equatorial has proceeded at an accelerated pace, 1508 parallax plates having been taken, and 651 plates measured.

The determination of the 'colour-temperatures' of stars has been continued with the 30 -inch reflector. The observation of 24 star's selected as standards has been completed ; these are now available as a base to which other stars can be referred. The absolute temperatures of the standards are now being found by comparison with an are lamp, which in turn will be compared with a gas-filled lamp already calibrated at Utrecht.

The astrographic equatorial, which had been sent to Siam for the solar eclipse, was remounted in July. Some renewals in the bearings and accessories were satisfactorily carried out by Messrs. Grubb, Parsons and Co. The Greenwich astrographic zone, decl. $64^{\circ}$ to $90^{\circ}$, is being re-photographed for the determination of proper motions by comparison with the earlier plates; the motions of 14,500 stars between $64^{\circ}$ and $72^{\circ}$ have now been published.

The sun was photographed on 270 days at Greenwich; plates taken at the Cape and Kodaikanal will render the record complete. The spot activity is definitely on the wane; there were, however, large spots in November and December. A spectrohelioscope has been lent to the Observatory by the Mount Wilson Observatory; it has been mounted in the south attic of the new building. A survey of the sun's disc in $H_{\alpha}$ light is made daily, when weather permits. Special attention is paid to the radial velocities of dark markings near sunspots.

Spot numbers for the whole dise, and for the central zone, are supplied regularly to Zurich for incorporation in the bulletin that is issued there under the auspices of the I.A.U.

The mean temperature of the year was $51 \cdot 0^{\circ}$, which is $1.5^{\circ}$ above the 75 -year average ; the extreme values were $90.5^{\circ}$ on Aug. 31 , and $25.4^{\circ}$ on Mar. $20 ;$ both dates are unusually late for the extreme readings. The rainfall was 25.43 inches, which is 1.19 in. above the average. The winter was a stormy one, and the mean daily air movement, 289 miles, is 5 miles above the average. The highest daily value was 847 miles on Dec. 7 ; the highest hourly value 62 miles on Jan. 12, which also had the greatest pressure, $38 \mathrm{lb}$. per sq. ft.

The following are the mean values of the magnetic elements for 1929, obtained at Abinger; Decl. $12^{\circ} 35 \cdot 8^{\prime}$ W.; Hor. Force 0.18555: Vert. Force $0 \cdot 42918$ : $\mathrm{Dip} 66^{\circ} 37 \cdot 2^{\prime}$. It is noted in the report that a more precise instrument for determining the vertical force and dip was lent by the National Physical Laboratory; it revealed a small systematic error in the values given by the dip inductor; the error was 0.00010 in Vert. Force, $0.3^{\prime}$ in Dip.

The performance of the Shortt clocks continues to be satisfactory; in the sidereal clock No. 3 an invar bob was substituted for the type-metal one; the latter contained lead, and a certain amount of settling appears to have gone on, causing an increase of losing rate. This increase still goes on with the new bob, but at only half the former rate.

Rhythmic time signals from the Observatory are distributed by the wireless station at Rugby at $10 \mathrm{~h}$. and $18 \mathrm{~h}$. These, and the signals sent to the Post Office and the B.B.C., are controlled by the clock Shortt No. 16.

The following are the mean amounts by which the time signals from other stations are late on Greenwich: Paris 0.044 sec. : Nauen 0.006 sec.: Annapolis (near Washington) $0.007 \mathrm{sec}$. Bordeaux $0.035 \mathrm{sec}$. These are after corrections for lag and time of travel have been applied.
A. C. D. Crommelin.

\section{An Early Letter from Darwin to Owen.}

THE letter printed below was bought at Sotheby's in March of this year for the Fitzwilliam Museum, Cambridge, by some friends of that institution. It was written rather more than two months after Darwin's return in the Beagle. The fossil vertebrates referred to in the letter were sent to the Royal College of Surgeons. Darwin wrote to Owen, who was five years his senior, as a young man addressing a more experienced and older colleague: later the two became friends and Owen visited Down in 1848. Twelve years later, in a letter to de Quatrefages, Darwin wrote: "I have been atrociously abused by my religious countrymen; but as I live an independent life in the country, it does not in the least hurt me in any way, except indeed when the abuse comes from an old friend like Professor Owen, who abuses me and then advances the doctrine that all birds are probably descended from one parent" ("More Letters of Charles Darwin ", vol. 1, p. 202). Reference is made to Darwin's attitude towards Owen in a note printed at the head of a letter to Hugh Falconer (1863) on page 226 of vol. 2 of "More Letters".

Darwin settled at Cambridge on Dec. 10, 1836 : he was at first a guest in the home of the Henslows, and later went into lodgings at a house in Fitzwilliam Street, on which a tablet has been fixed. The letter was written as from Christ's College, though he was presumably not actually in residence there.

A. C. S.

My dear Sir,

Decemb 19th (1836)

I have just written and will send it the same time with this, a letter to Sir Ant: Carlisle. I have done exactly as you recommended me. I thought myself compelled to fix on the British Museum in preference to that of Paris because I was carried on board a King's Ship ; and the public collection of the country certainly has claims on me. If the collection had been made entirely at my own expense, that is on board a Merchant vessel, then I should not have hesitated in making a different choice. I quite agree with you that the British Museum ought to make returns when it has the power. I suppose you could not venture to propose another set for Paris. Their value would be so much more in that collection than in the British Museum. I ought to make up my mind to give my own set to Paris; but I confess I should be grieved to lose my trophies. I should feel like a knight who had lost his armorial bearings. If the Council should not choose to go to the expense necessary for making all the casts; it was suggested to me here, that the 